\title{
COVID19: Dexamethasone; death or deliverer therefrom?
}

\author{
Robinson $\mathbf{J}^{1}$, Banerjee $\mathrm{I}^{2 *}$, Annavarapu $\mathrm{A}^{3}$, Leclézio $\mathrm{A}^{4}$
}

\section{*Corresponding author:}

Dr. Indrajit Banerjee

Associate Professor, Department of Pharmacology, Sir Seewoosagur Ramgoolam Medical College, Mauritius

Email: indrajit18@gmail.com $\underline{\text { ORCID }}$

\section{Information about the article:}

Received: June 18, 2020

Accepted: June 24, 2020

Published online: June 30, 2020

\section{Cite this article:}

Robinson J, Banerjee I, Annavarapu A, Leclézio A. COVID19: Dexamethasone; death or deliverer therefrom? Journal of Biomedical Sciences. 2020;7(1):47-51

\section{Publisher}

Nepal Health Research Society, Bahundhara -6, Gokarnesowor Municipality, Kathmandu, Nepal eISSN 2382-5545, ISSN 2676-1343 (Print)

(c) The Author(s). 2020

Content licensing: CC BY 4.0

\section{ABSTRACT}

\section{Background}

A multitude and wide array of various drugs have been postulated and some even attempted to be used as effective treatments against the virus. The drugs have ranged from antimalarials used in India as a prophylaxis to the disease; namely chloroquine and hydroxychloroquine, to the use of broad-spectrum antiviral drugs such as Remdesivir. Dexamethasone, a cheap, widely available, long acting corticosteroid has been gaining popularity and to some extent fame in the treatment of COVID19 patients.

The benefits and use thereof were made apparent after very successful research conducted by the University of Oxford. The Recovery trial, which is one of the world's largest clinical trials. This trial reported on June 16, 2020 that patients on Dexamethasone at a dosage of $6 \mathrm{mg}$ per day for 10 days have a dramatically reduced mortality particularly in the COVID patients on ventilators. The dexamethasone proved very beneficial in the milder cases of the disease as well and reduced death by $20 \%$ in those cases. The proposed mechanism of action by which the dexamethasone drug acts is via impeding the dangerous cytokine storm, an intense immune response that severely renders the lungs damaged. This intense cytokine storm is attributed to the severe complications and respiratory failure noted in COVID19 patients. The long acting dexamethasone would suppress this autoimmune destruction and intense inflammatory reaction, thereby sparing the lungs and the patient's life.

\section{Conclusion}

It is therefore of paramount importance that the use of dexamethasone in COVID19 cases is further studied and understood. The benefits of the use of dexamethasone are undeniable and therefore the drug should be implemented into the treatment regime with a guarded approach.

\section{Keywords}

Corticosteroids, COVID-19, Dexamethasone, drug, mechanism of action, treatment, vaccine 


\section{Background}

The world stands at a precipice of an unfounded and never before encountered race, the race to synthesize and develop a reliable, safe and cost-effective drug. A drug which can be used for the prophylaxis and treatment of the disease caused by COVID19. Current statistics project that if such a drug is not obtained or synthesized in the near future, it could relate to the loss of hundreds of thousands of human lives.

\section{The current trials}

The global pharmaceutical giants have attempted to develop such a vaccine to aid in retarding the virulent and tenacious spread of the virus. In this current stage of the pharmaceutical race there are more than 109 vaccines which find themselves in trials: namely the pre-clinical evaluation. A subtotal of 9 of these vaccines are at the clinical evaluation stage [1-3].

The lack of a successful vaccine produced till date and the combined effect of the lives and immense enormity and empirical importance and nature of such a task has appealed to the humanitarian side of many of these capitalistic pharmaceutical companies and ventures. This has allowed for the birth of an international clinical trial known as "Solidarity" (ISRCTN83971151). The goal of this initiative is to rapidly ascertain whether any of the drugs retard the progression or improve the survival of patients suffering from COVID19 [4-5].

The United Kingdom is host to the globes largest clinical trial to determine whether drugs such as lopinavir, ritonavir, dexamethasone, hydroxychloroquine, and azithromycin can be repurposed to be used in COVID+ patients. This clinical trial will be adaptive in nature to accelerate the identification of effective treatments [6].

\section{Therapeutic postulations}

A multitude and wide array of various drugs have been postulated and some even attempted to be used as effective treatments against the virus. The drugs have ranged from antimalarials used in India as a prophylaxis to the disease; namely chloroquine and hydroxychloroquine (HCQ) [7], to the use of broad-spectrum antiviral drugs such as Remdesivir in China [8]. The proverbial picture for a possible treatment of the virus was further mudded by the fact that ACE-2 inhibitor medication was initially hypothesized to be damaging and then shortly after proven to be somewhat beneficial in nature [9].

On conducting a systematic review of COVID19 and the relative treatments undergoing trials, a pattern of continued positive results and potential was noted with the use of Corticosteroids. On further investigation it seems likely that a potential drug which is very widely available may be a dominant and effective weapon in the arsenal of therapies used to combat the virus.

\section{Dexamethasone}

Dexamethasone, a cheap, widely available, long acting corticosteroid which has been gaining popularity and to some extent fame in the treatment of COVID19 patients. Dexamethasone is a synthetic and low-cost steroid; it is widely available in throughout the world. Dexamethasone has selective glucocorticoid actions with zero of the mineralocorticoid effects. Dexamethasone is a very potent corticosteroid and it has a long duration of action. Dexamethasone's elimination half- life is around 3 hours and it's biological plasma half - life is more than 36 hours [10].

The benefits and use thereof were made apparent after very successful research conducted by the University of Oxford. The Recovery trial, which is one of the world's largest clinical trials. This trial reported on June 16, 2020 that patients on Dexamethasone at a dosage of $6 \mathrm{mg}$ per day for 10 days have a dramatically reduced mortality particularly in the COVID patients on ventilators. The dexamethasone proved very beneficial in the milder cases of the disease as well and reduced death by $20 \%$ in those cases. The value and beauty of this data is that dexamethasone is now the only drug in the world that has proven to show tangible positive lifesaving effects when used in the protocols for the treatment in severely ill COVID-19 individuals [11].

Oxfords Recovery trial has revealed very positive results in favor of the use of dexamethasone. 94 out of 324 ventilated patients on dexamethasone passed on; whereas a proportionally higher 278 out of 683 patients without treatment with dexamethasone passed on. The use of dexamethasone therefore decreased the death rate from $40.7 \%$ to $29 \%$. Similar findings were present for patients receiving oxygen therapy as 275 out of 1279 treated with dexamethasone passed on; whereas 650 out of 2064 being treated without dexamethasone passed on. This portraying a decreased death rate from $25 \%$ to $21.5 \%$. The same cannot be said for the use of dexamethasone in patients receiving no respiratory support as 85 out of 501 patients being treated with dexamethasone passed on; whereas 137 out of 1034 patients being treated without dexamethasone passed on [12].

\section{Mechanism of action}

The mechanism of action of corticosteroids at a molecular level is that it binds to the cytoplasmic glucocorticoid receptors and stimulates the glucocorticoid response elements (GRE), then transcription of m-RNA and gene medicated cellular actions. Based upon this dexamethasone produces it's actions to be specific its anti-inflammatory and immunosuppressant actions. As an anti-inflammatory it will inhibit leucocyte migration into the inflamed tissue, it will cause stabilization of lysosomal membranes, decrease capillary permeability, suppress the chemokines as well as the proinflammatory cytokines. Dexamethasone will concomitantly cause the reduction of 
chemotaxis by monocytes and neutrophils, Inhibit the phospholipase-A2, hence inducing a decrease in the production prostaglandins, leukotrienes and platelet activating factor. As an immunosuppressant dexamethasone has anti allergic actions such as inducing the inhibition of the activation of cytotoxic $\mathrm{T}$ lymphocytes and their proliferation, suppression of cellmediated hypersensitivity, it inhibits the function of macrophages and reduce their ability to respond to antigens. This affects phagocytosis. Further, production of $\mathrm{TNF} \alpha$, interleukins (interleukin-1, interleukin-12, and interleukin-18), interferon-gamma is reduced. The clinical uses of dexamethasone is to treat certain lung diseases like bronchial asthma, chronic obstructive pulmonary disease (COPD), severe acute respiratory distress syndrome (ARDS), Pneumonia as well as other conditions like multiple sclerosis, shock, rheumatologic disorders, meningitis, cerebral edema, certain types of cancers and is also used as an adjuvant drug to treat emesis like postoperative nausea and vomiting (PONV) and chemotherapy induced nausea and vomiting (CINV) [13, 14].

\section{Mechanism of action of Dexamethasone in COVID 19}

The proposed mechanism of action by which the dexamethasone drug acts is via impeding the dangerous cytokine storm, an intense immune response that severely renders the lungs damaged. This intense cytokine storm is attributed to the severe complications and respiratory failure noted in COVID19 patients. The long acting dexamethasone would suppress this autoimmune destruction and intense inflammatory reaction, thereby sparing the lungs and the patient's life [15].

\section{Supportive research and data}

It must be noted that this is not the first-time dexamethasone and related drugs have been found to be useful in such severe respiratory conditions. A Randomised control Test in Spain conducted by Villar et al during 2013-2018, administered intravenous dexamethasone to 139 patients who had moderate-tosevere ARDS and found that the mean number of ventilator-free days was higher in the patients on dexamethasone therapy as compared to the control group. The results showed that early dexamethasone treatment could reduce the number of days that ARDS patients require mechanical ventilation, and it could reduce their overall mortality [16].

The use of the dexamethasone group of drugs is further supported by early findings in China. A study in Wuhan found that the administration of methylprednisolone significantly reduced the risk of death in Chinese patients. Among patients with ARDS, those who received methylprednisolone treatment 23 out of $50(46 \%)$ died while those who weren't on treatment 21 of $34(62 \%)$ died. This proves that there was a considerably lower risk of death in COVID-19 ARDS in patients who received this systemic synthetic corticosteroid treatment [17].

\section{Limitations and therapeutic usage}

The use of dexamethasone, which is a high-level corticosteroid does not present itself as a completely riskfree therapeutic option. The dexamethasone group of drugs are lifesaving in nature but, must be used with the upmost level of caution in certain conditions. One of these conditions is diabetes mellitus which has become and established as well as one of the most prevalent risk factors in patients with COVID19 who develop further life-threatening complications [18]. A study conducted by Theoharides et al, stipulates that the use of dexamethasone, is double edged in nature as dexamethasone is immunosuppressive in mechanism. This very action of the drug could be problematic in mild cases of COVID19, as dexamethasone would suppress both the local and systemic immunity and could thereby induce and create the environment for a superimposed secondary infection [15].

\section{Solutions and therapeutic regimen alterations to diminish the limitations}

The overview of the limitations dictates that the use of dexamethasone on critically ill patients in the short term would be beneficial but would be catastrophic in milder cases in the recovery period, due to the immunosuppressive nature of the drug. Theoharides et al, has proposed a pulse therapy with dexamethasone followed by the concomitant nebulization of the patient with nebulized triamcinolone. The triamcinolone concentrating in the lung and thus having the added effect of the drug without the adverse effect [15].

\section{Global supply and therapeutic availability}

The current global pharmaceutical market and trade is pivoted on the COVID situation and its developments. The supply and demand for various drugs has skyrocketed and subsequently collapsed due to theories and the subsequent invalidation of those theories in the treatment of the virus. The case of dexamethasone is no exception. In light of this recent discovery the global demand and requirement for dexamethasone has seen a cataclysmal surge. This is due to the up surging nature of the number of patients with the virus. The global challenge is now to ensure that there is a sufficient supply of dexamethasone to meet the growing international demand. An increase in production of dexamethasone will need to be orchestrated by pharmaceutical companies in order to save lives [12].

\section{Conclusion}

It is therefore of paramount importance that the use of dexamethasone in COVID19 cases is further studied and understood. The benefits of the use of dexamethasone are 
undeniable and therefore the drug should be implemented into the treatment regime with a guarded approach. The world stands at a precipice of an unfounded and never before encountered race, the race to synthesize and develop a reliable, safe and cost-effective drug. A drug which can be used for the prophylaxis and treatment of the disease caused by COVID19. Current statistics project that if such a drug is not obtained or synthesized in the near future, it could relate to the loss of hundreds of thousands of human lives.

\begin{abstract}
Abbreviations
Acute respiratory distress syndrome (ARDS), chronic obstructive pulmonary disease (COPD), Corona virus disease (COVID-19), glucocorticoid response elements (GRE), Hydroxychloroquine (HCQ), Post-operative nausea and vomiting (PONV) and chemotherapy induced nausea and vomiting (CINV)
\end{abstract}

\section{Acknowledgments}

We extend our intense gratitude to the Chairman Mr. RPN Singh and Prof. Namrata Chhabra, Principal In charge, SSR Medical College, Mauritius for providing us with huge support and guidance to conduct the research study effectively.

\section{Authors' contribution}

a. Study planning: IB

b. Manuscript writing: JR, IB, AA, AL

c. Manuscript revision: JR, IB

d. Final approval: JR, IB, AA, AL

e. Agreement to be accountable for all aspects of the work: JR, IB, AA, AL

\section{Funding}

The authors have not received any funding's for this work.

\section{Availability of data and materials}

All data and materials available as part of the article, and no additional source data are required.

\section{Competing interests}

None declared.

\section{Publisher's Note}

NHRS remains neutral with regard to jurisdictional claims in published maps and institutional affiliations.

The publisher shall not be legally responsible for any types of loss, actions, claims, proceedings, demand or costs or damages whatsoever or howsoever caused arising directly or indirectly in connection with or arising out of the use of this material.

\section{Author information}

${ }^{1} \mathrm{Mr}$. Jared Robinson, ORCID

${ }^{2}$ Dr Indrajit Banerjee, Associate Professor, ORCID

${ }^{3} \mathrm{Mr}$. Amarendra Annavarapu, Assistant Professor, ORCID

${ }^{4}$ Alexandra Leclézio, ORCID

${ }^{1} 2^{\text {nd }}$ Professional medical student, Sir Seewoosagur Ramgoolam Medical College, Mauritius

${ }^{2,3}$ Department of Pharmacology, Sir Seewoosagur Ramgoolam Medical College, Mauritius

${ }^{4}$ Final Part 2 medical student, Sir Seewoosagur Ramgoolam Medical College, Mauritius

\section{References}

1. Randomized, double-blind, placebo-controlled phase II clinical trial of recombinant new coronavirus (2019-nCOV) vaccine (adenovirus vector) [online] 2020 [cited 2020 June 17] Available from: URL: http://www.chictr.org.cn/showproj.aspx?proj=5200 $\underline{6}$

2. Phase I clinical trial of recombinant new coronavirus (2019-COV) vaccine (adenovirus vector) [online] 2020 [cited 2020 June 17]. Available from: URL: http://www.chictr.org.cn/showproj.aspx?proj=5115 $\underline{4}$

3. Draft landscape of COVID-19 candidate vaccines. [online] 2020 [cited 2020 June 17]. Available from: URL: https://www.who.int/who-documentsdetail/draft-landscape-of-covid-19-candidatevaccines

4. "Solidarity" clinical trial for COVID-19 treatments [online] 2020 [cited 2020 June 17]. Available from:

https://www.who.int/emergencies/diseases/novelcoronavirus-2019/global-research-on-novelcoronavirus-2019-ncov/solidarity-clinical-trial-forcovid-19-treatments

5. Available from: https://clinicaltrials.gov/ [online] 2020 [cited 2020 June 17].

6. Biggest COVID-19 trial tests repurposed drugs first. Nat Biotechnol. 2020;38(5):510. https://doi:10.1038/s41587-020-0528-X

7. Gupta N, Agrawal S, Ish P. Chloroquine in COVID-19: the evidence. Monaldi Arch Chest Dis. 2020;90(1):10.4081/monaldi.2020.1290. https://doi.org/10.4081/monaldi.2020.1290

8. Wang M, Cao R, Zhang L, Yang X, Liu J, Xu M, et al. Remdesivir and chloroquine effectively inhibit the recently emerged novel coronavirus (2019-nCoV) in vitro. Cell Res. 2020;30(3):26971.

https://doi.org/10.1038/s41422-020-0282-0

9. Sun ML, Yang JM, Sun YP, Su GH. Zhonghua Jie $\mathrm{He} \mathrm{He} \mathrm{Hu} \mathrm{Xi}$ Za Zhi. 2020;43(0):E014. 
https://doi.org/10.3760/cma.j.issn.10010939.2020.0014

10. Loew D, Schuster O, Graul EH. Dose-dependent pharmacokinetics of dexamethasone. Eur J Clin Pharmacol.1986;30(2):225-30. https://doi.org/10.1007/BF00614309

11. Ledford H. Coronavirus breakthrough: dexamethasone is first drug shown to save lives. Nature. 2020;10.1038/d41586-020-01824-5. https://doi.org/10.1038/d41586-020-01824-5

12. Mahase E. Covid-19: Demand for dexamethasone surges as RECOVERY trial publishes preprint. BMJ.2020;369:m2512. https://doi:10.1136/bmj.m2512

13. Al Katheeri NA, Wasfi IA, Lambert M, Saeed A. Pharmacokinetics and pharmacodynamics of dexamethasone after intravenous administration in camels: effect of dose. Vet Res Commun. 2004;28(6):525-42.

https://doi.org/10.1023/B:VERC.0000040243.3019 $\underline{9.1 \mathrm{f}}$

14. Giles AJ, Hutchinson MND, Sonnemann HM, Jung J, Fecci PE, Ratnam NM, et al. Dexamethasone-induced immunosuppression: mechanisms and implications for immunotherapy. J Immunother Cancer. 2018;6(1):51. https://doi.org/10.1186/s40425-018-0371-5

15. Theoharides TC. Dexamethasone for COVID-19? Not so fast. J Biol Regul Homeost Agents. 2020 Aug 31;34(4). http://doi.org/10.23812/20-EDITORIAL 1-5.

16. Villar J, Ferrando C, Martínez D, Ambrós A, Muñoz T, Soler JA, et al. Dexamethasone treatment for the acute respiratory distress syndrome: a multicentre, randomised controlled trial. Lancet Respir Med. 2020;8(3):267-76. https://doi.org/10.1016/S2213-2600(19)30417-5

17. Wu C, Chen X, Cai Y, Xia J, Zhou X, Xu S, et al. Risk Factors Associated With Acute Respiratory Distress Syndrome and Death in Patients With Coronavirus Disease 2019 Pneumonia in Wuhan, China. JAMA Intern Med. 2020;e200994. https://doi.org/10.1001/jamainternmed.2020.0994

18. Guo W, Li M, Dong Y, Zhou H, Zhang Z, Tian C, et al. Diabetes is a risk factor for the progression and prognosis of COVID-19. Diabetes Metab Res Rev. 2020;e3319. https://doi.org/10.1002/dmrr.3319 